\title{
Coupling of air quality and weather forecasting - progress and plans at met.no
}

\author{
Viel Ødegaard, Leonor Tarrasón and Jerzy Bartnicki \\ Norwegian Meteorological Institute
}

\section{Introduction}

Air quality modelling at met.no consists of three different systems, all coupled off-line to our numerical weather prediction models. These are: 1) a nuclear emergency system, 2) an urban air quality forecasting system and 3) a long-term air quality chemical transport model routinely used in Europe to determine transboundary pollution fluxes.

The first system, the "Severe Nuclear Accident Program" (SNAP) model was developed at met.no to allow emergency risk assessment (Saltbones et al., 1995, 1998). This is a Lagrangian particle model transporting gases, noble gases, particles of different size and density. The modeled processes are advection and diffusion by random walk, dry deposition with gravitational settling velocity parameterization for particles and wet deposition as function of size and precipitation for particles. The model is operated by forecasters and the Norwegian Radiation Protection Authority in case of nuclear accident. It runs on meteorological input from operational HIRLAM (10 and $20 \mathrm{~km}$ horizontal resolution) and from ECMWF (Bartnicki et al., 2005).

The second system, the urban air quality information system runs operationally at met.no and consists of the chemical dispersion model AirQUIS developed at Norwegian Institute for Air Research and the non-hydrostatic NWP model MM5 in $1 \mathrm{~km}$ horizontal resolution nested in HIRLAM (Berge et al., 2002). AirQUIS is a Eulerian gridpoint model with point source emissions, line source emissions and area source emissions. The prognostic components of the model are $\mathrm{PM}_{10}$, cities in 1x $1 \mathrm{~km}$ horizontal resolution in both meteorological and air quality model. It is used $\mathrm{PM}_{2.5}$ and nitrogen dioxide $\left(\mathrm{NO}_{2}\right)$.The system runs daily 48 hours forecasts for 6 Norwegian cities, with main focus in forecasting urban air quality during winter season. The cities under study are located in low elevated areas surrounded by hills and mountains. Winter time inversions inhibit ventilation of pollution and thus main exceedances of critical pollution levels occur in Norway during winter. The forecasts are distributed to end-users via newspapers, mobile network and internet.

The third system is the chemical transport model supporting the modeling work under under the Co-operative programme for monitoring and evaluation of the long transmission of Air Pollutants in Europe (the EMEP programme). The model used, the EMEP Unified model is developed at met.no for simulating atmospheric transport and deposition of acidifying and eutrophying compounds, aerosols as well as photo-oxidants over Europe. The model is a multi-layer Eulerian model and is 
now flexible with respect to the choice of horizontal grid projection, domain and resolution. The model can thus be run at local, regional, hemispheric and global scale. Typically, the model simulates one year period of the transport and the current results of the regional model runs are available for the years 1980, 1985, 1990 and each year from 1995 to 2004. The EMEP Unified in operational configuration is the regional version that uses presently HIRLAM PS, a dedicated version of HIRLAM, which has been frozen for last 10 years and runs on a polar stereographic grid with 50km resolution and a model domain that covers Europe and the Atlantic Ocean. In vertical, the model has 20 sigma layers reaching up to $100 \mathrm{hPa}$. Approximately 10 of these layers are below $2 \mathrm{~km}$ to obtain high resolution of the boundary layer. The polar stereographic projection is historically bound to the EMEP reporting grid for emissions over Europe. A detail description of the model can be found at Simpson et al., 2003 and validation results are available at Tarrason (ed)., 2003. The EMEP model is also run at regional scale in forecast mode with input from ECMWF Integrated Forecasting system (IFS). Initial results from these forecasts that have been running for 10 months are under evaluation and will be reported in due time. The hemispheric and global version of the model are run respectively on ECMWF ERA data and ECMWF IFS archived data. A summary of the model performance in hemispheric and global scale can be found at Jonson et al., 2006 and Jonson et al., 2007.

\section{Off-line coupling of meteorological and chemical transport models}

The SNAP model runs with input from available operational HIRLAM, at present the version running on 20km horizontal resolution provides a sufficiently large domain for SNAP. The most important meteorological input is 3-D wind fields and precipitation. The time resolution for meteorological input is 3-hourly in operational applications, but 1-hourly data has been used for the historical simulations.

The AirQUIS model runs with input from MM5 in 1-hourly time resolution. The transferred 2-D surface parameters are precipitation, total cloud cover, mixing height and surface temperature. 2-D parameters from lowest model level are temperature, dew point temperature, relative humidity and the vertical temperature gradient. The horizontal wind is the only 3-D parameter used. A horizontal interpolation from polar stereographic grid to utm is taking place. At present no vertical interpolation is done. The vertical levels in AirQUIS are defined to be identical to the levels in MM5. A meteorological preprocessor calculates dispersion parameters based on Monin-Obukhov similarity theory. The constant parameters topography and surface roughness are taken from the meteorological model.

The Unified EMEP models uses the 3-D fields horizontal and vertical wind, specific humidity, potential temperature cloud cover and precipitation. The transferred surface 2-D fields for use in the chemical transport model are: surface pressure, $2 \mathrm{~m}$ temperature, surface flux of momentum, sensible and latent heat and surface stress. All variables are in 3-hourly resolution. Table 1 lists the variables and their main purpose in the EMEP model. Inside the EMEP model different boundary layer parameters like stability, eddy diffusion and mixing height are calculated based on similarity theory. 


\begin{tabular}{|c|c|c|c|}
\hline Parameter & Unit & Description & Main Purpose \\
\hline \multicolumn{4}{|c|}{ 3D fields - for $20 \sigma$ levels } \\
\hline $\mathrm{u}, \mathrm{v}$ & $\mathrm{m} / \mathrm{s}$ & W ind velocity components & Advection \\
\hline q & $\mathrm{kg} / \mathrm{kg}$ & Specific hum idity & Chem ical reactions, dry deposition \\
\hline$\dot{\sigma}$ & $s^{-1}$ & Vertical w ind in $\sigma$ coordinates & vertical advection \\
\hline$\theta$ & K & Potential tem perature & Chem ical reactions, eddy diffusion \\
\hline CL & $\%$ & Cloud cover & Wet removal, photolysis \\
\hline$P R$ & $\mathrm{~m} \mathrm{~m}$ & Precipitation & Wet and dry deposition \\
\hline \multicolumn{4}{|c|}{ 2D fields - for Surface } \\
\hline Ps & $\mathrm{hPa}$ & Surface pressure & Surface air density \\
\hline $\mathrm{T}^{2}$ & K & Temperature at $2 \mathrm{~m}$ height & Dry deposition, stability \\
\hline $\mathrm{H}$ & $\mathrm{W} \mathrm{m}^{-2}$ & Surface flux of sensible heat & Dry deposition, stability \\
\hline$\tau$ & $\mathrm{M} \mathrm{m}^{-2}$ & Surface stress & Dry deposition, stability \\
\hline LE & $\mathrm{W} \mathrm{m}^{-2}$ & Surface flux of latent heat & Dry deposition \\
\hline
\end{tabular}

Table 1. Variables transferred from HIRLAM to EMEP(from Simpson et al., 2003)

\section{Evaluation of urban air quality forecasts}

Regular forecasts are produced with MM5/AirQUIS. The meteorological and the air quality forecasts are evaluated against observations and reported on a yearly basis. Summary statistics and case studies are produced. In Figure 1 forecasts for the air quality station Alnabru is compared to air quality observations at Alnabru and to meteorological observations at the two closest stations Valle Hovin and Blindern. The missing peak in the $\mathrm{NO}_{2}$ forecasts is not caused by errors in the meteorological forecasts. However the air quality monitoring station is not located together with the meteorological station. Neither does the meteorological station measure all the parameters that go into the air quality model. Observations of inversion layer are limited to measurements of temperature in 2 and $25 \mathrm{~m}$ in the presented case. 

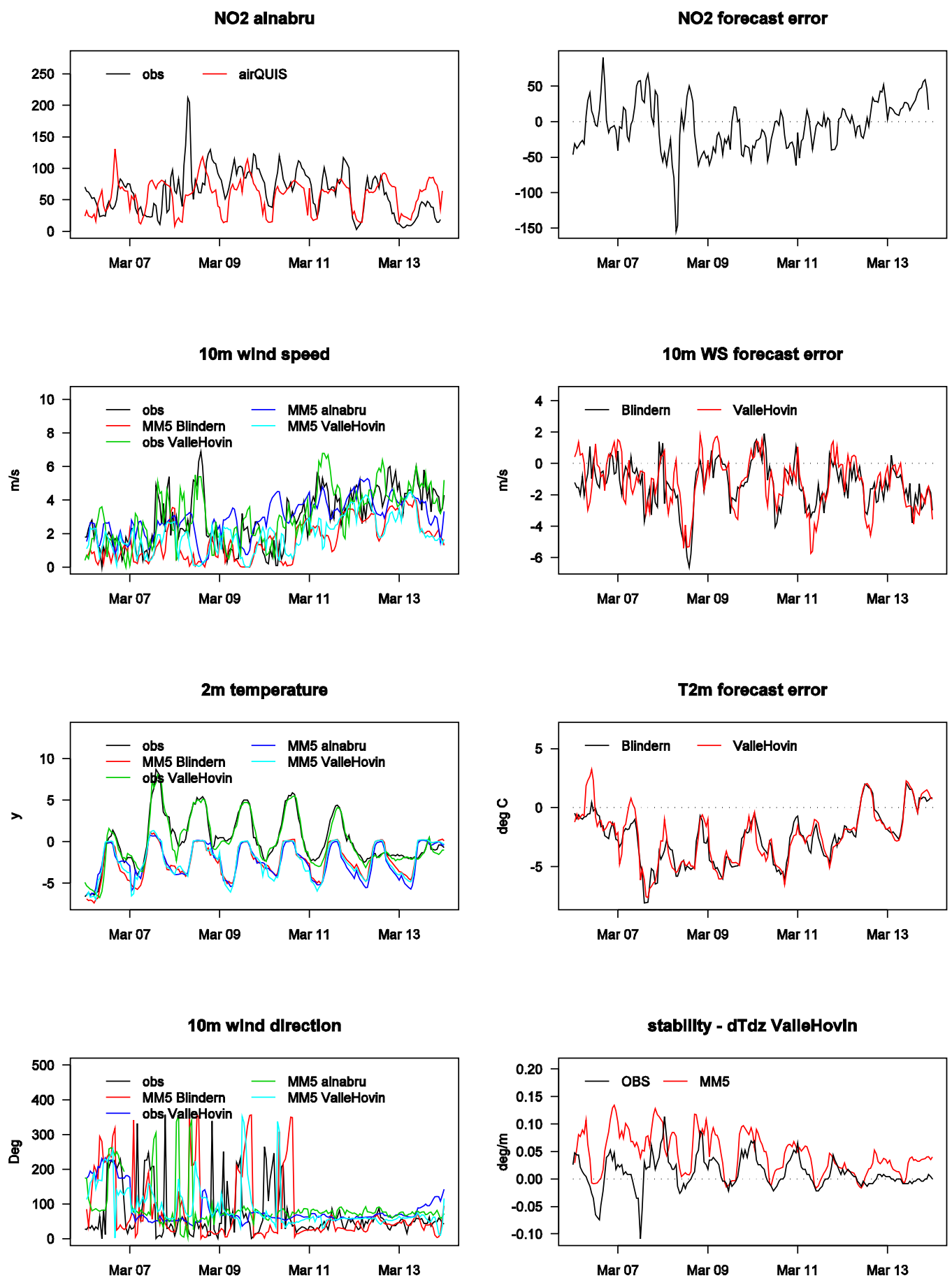

Figure 1. Observations (black) and model forecasts of $\mathrm{NO}_{2}$, wind speed, $2 \mathrm{~m}$ temperature and wind direction (left), and forecast error for $\mathrm{NO}_{2}$, wind speed and $2 \mathrm{~m}$ temperature (right) at two different observations sites. Forecasts (red) and observations (black) of vertical temperature gradient 2-25m (bottom right) (from Ødegaard et al., 2004). 
Experiments have been performed to address the error made by the pre-processor in AirQUIS. Figure 2 shows the resulting NO2 forecasts from AirQUIS using dispersion parameters calculated by the pre-processor compared to AirQUIS using dispersion parameters calculated by the meteorological model MM5.
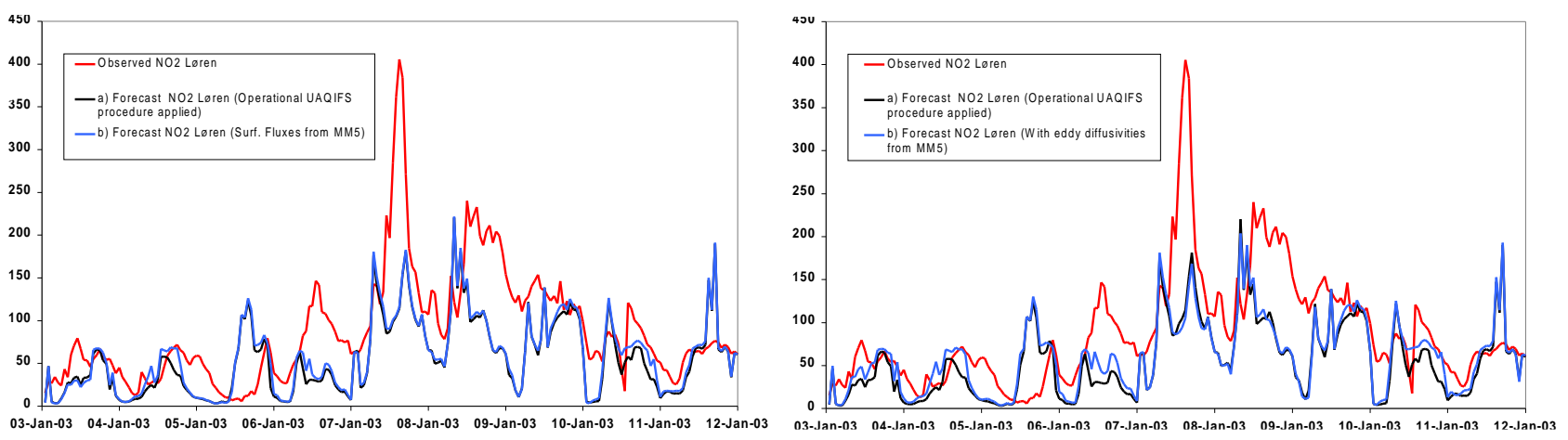

Figure 2. NO2 forecasts from AirQUIS using surface fluxes (left) and eddy diffusivities (right) from pre-processor (black) and from MM5 (blue) compared to observations (red) (from Slørdal and Ødegaard, 2005)

Both in the pre-processor and in MM5 the dispersion parameters are calculated using Monin-Obukov similarity theory. The difference is therefore due to a timestep update of the parameters going into the parametrization scheme rather than an hourly update in the pre-processor. The figure shows that this difference has very small impact on the results.

\section{Issues to consider for NWPmodels providing data for air pollution models}

All air pollution modeling systems at met.no are presently developing to include other types of meteorological drivers at finer resolution. For instance, a small scale SNAP version for simulating local effects in the range of $30-50 \mathrm{~km}$ is planned for 2007. Further a coupling to UK Met Office Unified model (UM) model or small scale HIRLAM model will be made for even higher resolution SNAP. Also a full coupling of SNAP to regional HIRLAM model is in the line, i.e. SNAP as subroutine in HIRLAM code. During the winter season 2006/2007 the UK Met Office Unified model has been introduced to replace MM5, and a new interface to AirQUIS is built. Also the EMEP model is developing to use different main sets of meteorological data, ECMWF, HIRLAM and the non-hydrostatic models Weather Research and Forecasting Model (WRF), the UK Met OfficeUnified Model and ALADIN.

For all these applications, special attention should be given to the interfaces between dynamical and chemical processes. While it is recognised that a on-line coupling of these processes will be ultimately necessary, there are still a series of processes that need special attention also under off-line applications, as named below. 


\subsection{Surface classes}

For consistent calculation of boundary layer parameters in off-line coupling the land-use classes in the meteorological model should ideally match the land-use classes present in EMEP (Table 2). In the coupling with HIRLAM where five land-use classes are present only, and no parameters to distinguish needle leaf forest from broad leaf forest, is thus not fully consistent.

\subsection{Physical parameterizations}

CTM models can make use of atmospheric parameters that are output from some parameterization schemes. Boundary layer parameters have to be calculated inside CTM models or in pre-processing if not available from the meteorological model. Entrainment and detrainment rates in cumulus clouds is could be provided if sufficiently sophisticated cumulus parameterization is used in the meteorological model.

\begin{tabular}{|l|l|l|}
\hline Surface/vegetation type & $\mathrm{H}(\mathrm{m})$ & Albedo $(\%)$ \\
\hline Temperate/boreal coniferous forests & $>20$ & 12 \\
\hline Temperate/boreal deciduous forests & $>20$ & 16 \\
\hline Mediterranean needle-leaf forests & 15 & 12 \\
\hline Mediterranean broadleaf forests & 15 & 16 \\
\hline Temperate crops & 1 & 20 \\
\hline Root crops & 1 & 20 \\
\hline Mediterranean crops & 2 & 20 \\
\hline Semi-natural moorland & 0.5 & 14 \\
\hline Grassland & 0.5 & 20 \\
\hline Mediterranean scrubs & 3 & 20 \\
\hline Wetlands & 0.5 & 14 \\
\hline Tundra & 0.5 & 15 \\
\hline Desert & 0 & 25 \\
\hline Water & 0 & 8 \\
\hline Ice & 0 & 70 \\
\hline Urban & 10 & 18 \\
\hline
\end{tabular}

Table 2. Surface types used by the EMEP model

\section{References}

Bartnicki J., B. Salbu, Saltbones J., Foss A. and O. C. Lind (2005) Atmospheric transport and deposition of radioactive particles from potential accidents at Kola nuclear power plant. Re-analysis of worst case scenarios. Norwegian Meteorological Institute. Oslo, Norway. Met.no research report No. 10/2005. ISSN-1503-8025.

Berge, E., S.E. Walker, A. Sorteberg, M.S. Lenkopane, H.T.B. Jablonska and M.Ø. Køltzow (2002) A real-time operational forecast model for meteorlogy and air quality during peak air pollution episodes in Oslo, Norway. Water, Air and Soil Pollution: Focus, 2, 745-757. 
Jonson, J.E., Wind, P., Gauss, M. Tsyro, S. Søvde, A.O., Klein, H. Isaksen, I.S.A. and Tarrasón, L. (2006) First results from the hemispheric EMEP model and comparison with the global Oslo CTM2 model, EMEP/MSC-W note 2/2006. Norwegian Meteorological Institute, Oslo, Norway.

Jonson, J.E., Tarrason, L., Wind, P., Gauss, M., Valiyaveetil, S.,Tsyro, S., Klein, H. Isaksen, I.S.A. and Benedictow, A. (2007) First evaluation of the global EMEP model and comparison with the global Oslo CTM2 model, EMEP/MSC-W Technical Report 2/2007. Norwegian Meteorological Institute, Oslo, Norway.

Saltbones J., Foss A. and J. Bartnicki (1995) Severe Nuclear Accident Program(SNAP) - A real time dispersion model. In: Proceedings of the 21 st NATO/CCMSMeeting on Air Pollution Modelling And Its Application, November 1995, Baltimore, USA. (S.E. Gryning and F.A. Schiermeier, eds.), pp. 333-340.

Saltbones J., Foss A. and J. Bartnicki (1998) Norwegian Meteorological Institute's Real-Time Dispersion Model SNAP (Severe Nuclear Accident Program). Runs for ETEX and ATMES II Experiments with Different Meteorological Input. Atmospheric Environment 32(24), 4277-4283.

Simpson, D., Fagerli, H., Jonson, J.E., Tsyro, S., Wind, P. and Tuovinen, J-P. (2003) Transboundary acidification, eutrophication and ground level ozone in Europe, Part I. Model Description. EMEP Status Report, 1/2003. Norwegian Meteorological Institute, Oslo, Norway.

Slørdal, H. and V. Ødegaard (2005) Dispersion conditions in the stable boundary layer as described by the MM5-model-A case study of a pollution episode in Oslo, Norway. Proceedings of $5^{\text {th }}$ International Conference on Urban Air Quality, 29-31 March 2005, Valencia, Spain

Tarrasón,L. (eds) (2003) Transboundary acidification, eutrophication and ground level ozone in Europe, Part II. Model Validation. EMEP Status Report, 1/2003. Norwegian Meteorological Institute, Oslo, Norway.

Ødegaard, V., K.I.Gjerstad, N.Bjergene, H.T.B.Jablonska and S.E.Walker (2004) Evaluation of a forecast model for meteorology and air quality winter 2003/2004 (In Norwegian). Norwegian Meteorological Institute. Oslo, Norway. Met.no research report No. 12/2004. ISSN-1503-8025. 